\title{
Therapeutic and preventive effects of Commiphora gileadensis against diethylnitrosamine-induced hepatic injury in albino rats
}

\author{
Doa'a Anwar, I. ${ }^{1 \star}$, Amani, S. ${ }^{2}$, Alzoreqy, A. ${ }^{2}$, Al-Dbhani, A. ${ }^{2}$, Al-Fteih, L. ${ }^{2}$, Abu-Al-fatah, T. $^{2}$, \\ QojaNazer, $\mathrm{H}^{2}$ and Alnoor, E. ${ }^{3}$ \\ ${ }^{1}$ Pharmacology Department, College of Pharmacy, University of Science and Technology, Sana'a, Yemen. \\ ${ }^{2}$ Histopathology Department Hospital Lab, University of Science and Technology, Sana'a, Yemen. \\ ${ }^{3}$ College of Pharmacy, University of Science and Technology, Sana'a, Yemen.
}

Received 29 May, 2015; Accepted 7 October, 2015

\begin{abstract}
Commiphora gileadensis is a tree in the burseraceae family, cultivated widely in Hadhramaut governorate (Yemen) and known locally as "Besham" or Balsam" used traditionally for many ailments. The aim of this study was to evaluate the therapeutic and preventive effects of $C$. gileadensis against diethylnitrosamine (DEN) -induced hepatic injury in albino rats. 40 albino rats were divided randomly into five groups (each contains 8 animals). Group I (Negative control) was given normal saline i.p and distilled water, group II (Positive control) toxicity-initiated with single dose of DEN $200 \mathrm{mg} / \mathrm{kg}$ i.p and promoted after 2 weeks with $0.05 \%$ of phenobarbitone in drinking water to complete 10 weeks. Group III was given $500 \mathrm{mg} / \mathrm{kg}$ extract of C. gileadensis bark for 10 weeks. Groups IV (preventive group) pretreated with $500 \mathrm{mg} / \mathrm{kg}$ extract of $C$. gileadensis bark and injected with DEN $200 \mathrm{mg} / \mathrm{kg}$ i.p for 10 weeks. Groups V (Treatment group) was given single dose of DEN same like group II but for 6 weeks, then treated with $500 \mathrm{mg} / \mathrm{kg} \mathrm{C}$. gileadensis bark extracts orally for an additional 4 weeks. All doses were used according to the effective dose fixation. Liver function enzymes, complete blood count (CBC) and lipid profile were measured. In addition, fasting blood sugar (FBS) and total body weight were taken weekly. At the end of experiment relative weight of liver was calculated. C. gileadensis showed significant hepatoprotective effect as it reduced the liver function enzyme's level, this effect was supported by hepatic histopathological improvement against DEN-induced hepatic injury. In addition, it demonstrated potent anti-platelets activity. The outcomes of this study suggested that $C$. gileadensis has novel hepatoprotective and remarkable anti- platelets effect.
\end{abstract}

Key words: Commiphora gileadensis, diethylnitrosamine, phenobarbitone, hepatic injury.

\section{INTRODUCTION}

Commiphora gileadensis (opobalsamum L.) or the Arabian balsam tree is one of a famous plant spread in the Arabian Peninsula especially Yemen, Saudi Arabia and Oman. The ancient product that is secreted from this

\footnotetext{
*Corresponding author. E-mail: anwar@hotmail.com.
} 
tree like resins or even the uses of woods cutting from plants were used for making perfumes, incense and different medical products (Jones, 1924). It is a member of the highly studied and commercially used resinous plant family burseraceae, comprising, among others, the biblical frankincense and myrrh (Zohary, 1973). It contains flavonoids, saponins, volatile oils, sterols and triterpenes (Zohary, 1982).

In Yemen, especially in Hadhramaut governorate this plant is used for thousands of years for many different ailments like skin disorders (wounds and burns), respiratory disease, gynecological purposes as contraceptive, labor pain, laxative and diuretic effect (Pliny, 1989). Nitrosamines are chemical compounds with the chemical structure $\mathrm{R} 1 \mathrm{~N}(-\mathrm{R} 2)-\mathrm{N}=\mathrm{O}$. They are used in the manufacturing of some cosmetics, pesticides, and most rubber products. Nitrosamine occurs in latex products such as balloons (Altkofer et al., 2005) and in many foods, and other consumables. Diethylnitrosamine chemically belonging to the N-Nitrosamine family is proved to be one of the potent carcinogens that is primarily metabolized by the cytochrome P-450 enzymes to reactive electrophiles (O6 alkyl-guanine and N7 alkylguanine) which are proved to be cytotoxic (Archer, 1989), carcinogenic (Swann and Magee, 1971) and mutagenic (Magee and Barnes, 1967). Moreover, phenobarbitone may promote the toxic effects induced by diethylnitrosamine (DEN) (Mohammed et al., 2014).

The aim of the present study is to evaluate the therapeutic and preventive effects of $C$. gileadensis against DEN-induced hepatic injury in albino rats.

\section{MATERIALS AND METHODS}

\section{Drugs and natural product}

$\mathrm{N}$-Nitrosodiethylamine (DEN) and phenobarbitone were purchased from Sigma-adrich Co. USA. C. gileadenesis bark was freshly collected in December, 2014 from Hadhramaut governorate. The plant was identified and authenticated at Botany Department, College of Science-, Sana'a University.

\section{Animals}

Experimental animals being Wister albino rats (Rattus norvegicus albinus), with average weight of $260 \pm 20 \mathrm{~g}$ and age of 3 to 4 months were obtained from the animal house of Biology Department, Sana'a University. They were allowed for one week to acclimatize and maintained in $12 \mathrm{~h}$ dark/light cycle. They were kept under free water and normal rat chow.

\section{Preparation of extract}

$1500 \mathrm{~g}$ of air-dried bark of $C$. gileadensis was powdered and macerated in $4 \mathrm{~L}$ of $99.9 \%$ of methanol for one week. The macerated barks then were put in Orbital shaker (0S10B-IKA®Werke- Germany) for further $48 \mathrm{~h}$ to mix all the contents of macerated preparation. Then filtered and the filtrate evaporated under reduced pressure using rotary evaporator (RE3022C-Stuart) at $40^{\circ} \mathrm{C}$. Repeated steps were done till the extraction of bark was completed. This process yielded about $24.39 \mathrm{~g}$ dark brownish color semi solid extract that was dissolved freshly in distilled water and given to animals (Al Howiriny et al., 2004).

\section{Animal study design}

Forty albino rats were divided randomly into five groups (each contains 8 animals). Group I (Negative control) was given normal saline i.p and distilled water. In group II (Positive control) toxicity was initiated with single dose of DEN $200 \mathrm{mg} / \mathrm{kg}$ i.p and promoted after 2 weeks with $0.05 \%$ of phenobarbitone in drinking water to complete 10 weeks. Group III was given $500 \mathrm{mg} / \mathrm{kg}$ extracts of $C$. gileadensis bark for 10 weeks. Groups IV (Preventive group) was pretreated with $500 \mathrm{mg} / \mathrm{kg}$ extract of $C$. gileadensis bark and injected with DEN $200 \mathrm{mg} / \mathrm{kg}$ i.p for 10 weeks. Groups V (Treatment group) was given single dose of DEN same like group II but for 6 weeks, then treated with $500 \mathrm{mg} / \mathrm{kg} \mathrm{C}$. gileadensis bark extracts orally for further 4 weeks. All doses were used according to the effective dose fixation according to method of Kalaiselvan et al. (2013). Aspartate aminotransferase (AST) (Schumann et al., 2002) and alanine aminotransferase (ALT) (Sonntag and Scholer, 2001), Alkaline phosphatase (ALP) (Abicht et al., 2001), lipid profile (Stein and Myers, 1995; Pisani et al., 1995; Bachoric, 2000) and complete blood count (CBC) were measured. In addition, fasting blood sugar (FBS) (Knudson and Weinstock, 2001) and total body weight were taken regularly. At the end of experiment relative weight of liver was calculated.

\section{Dose fixation study}

Different doses of C. gileadenesis extract (50, 100, 250, 500 and $750 \mathrm{mg} / \mathrm{kg}$ body weight) were used for 4 weeks in albino rats. The effective dose was based on the biochemical studies including liver and kidney function tests. The doses of 500 and 750 were found to be effective, but the minimum effective dose $(500 \mathrm{mg} / \mathrm{kg})$ was chosen and fixed throughout this study.

\section{Acute toxicity study}

Another twelve albino rats $(330 \pm 10 \mathrm{~g})$ were randomly divided into 3 groups, each contained 4 animals (the least no. was used for toxicological study). First group served as control group were only drunk distilled water, second and third groups were given extract of C. giladenesis bark $2 \mathrm{~g} / \mathrm{kg}$ and $3 \mathrm{~g} / \mathrm{kg}$ dissolved in distilled water. All animals were given the tested extract through oral gavage for $72 \mathrm{~h}$ according to the method of Jaykaran (2008). The following parameters were observed and measured:

1. Observational parameters: Mortality of animals, motor activity, tremors, convulsion, posture, spasticity, ataxia, writhing, skin color, diarrhea, salivation, lacrimation and respiration. Additionally, daily body weight and food intake were also noted. These observational parameters were monitored immediately at $0,2,4,8,24,48$ and 72 $\mathrm{h}$ of given tested extract.

2. Biochemical parameters: After $72 \mathrm{~h}$ of closed observation, animals were sacrificed by decapitation under anesthesia. Blood samples were collected for biochemical studies AST, ALT, CBC and FBS. Liver and heart were dissected out for histopathological examination. All the study procedures were in accordance with the guidelines for the care and use of laboratory animals, and approval was received prior to the experiments from the Institutional Research and Ethics Committee, UST. 
Table 1. Effect of $C$. giladenesis on the (mean \pm SE) liver function enzymes (AST, ALT and ALP) for 10 weeks in albino rats $(n=.8)$.

\begin{tabular}{lccc}
\hline \multirow{2}{*}{ Treatment } & \multicolumn{3}{c}{ Mean \pm SEM } \\
\cline { 2 - 4 } & AST (U/I) & ALT(U/I) & ALP(U/I) \\
\hline Control & $153.2 \pm 3.94$ & $37.6 \pm 3.86$ & $101.4 \pm 10.33$ \\
DEN & $281.0 \pm 23.87^{*}$ & $45.6 \pm 8.22$ & $162.0 \pm 4.93^{*}$ \\
Plant & $158.2 \pm 6.47^{* *}$ & $35.2 \pm 1.06$ & $95.8 \pm 7.72^{* *}$ \\
Preventive & $208.6 \pm 3.59^{* *}$ & $42.7 \pm 4.85$ & $106.2 \pm 19.88^{* *}$ \\
Treatment & $197.4 \pm 20.38^{* *}$ & $44.2 \pm 5.75$ & $103.4 \pm 18.12^{\text {** }}$ \\
\hline
\end{tabular}

*Significant as compared with control at $(\mathrm{P}<0.05),{ }^{* *}$ significant as compared with DEN- induced liver damage at $(\mathrm{P}<$ 0.05), AST: aspartate aminotransferase, ALT: alanine aminotransferase, ALP: alkaline phosphatase.

Table 2. Effect of $C$. giladenesis on the (mean \pm SE) body weight $(\mathrm{g})$ and relative weight of liver $(\mathrm{g})$ for 10 weeks in albino rats $(\mathrm{n}=8)$.

\begin{tabular}{lccccc}
\hline \multirow{2}{*}{ Parameter } & \multicolumn{5}{c}{ Mean \pm SEM } \\
\cline { 2 - 6 } & Control & DEN & Plant & Preventive & Treatment \\
\hline Initial body weight $(\mathrm{g})$ & $272.7 \pm 12.1$ & $274.2 \pm 14.0$ & $273.0 \pm 15.5$ & $277.8 \pm 14.2$ & $275.5 \pm 21.4$ \\
Final body weight $(\mathrm{g})$ & $320 \pm 12.7$ & $252 \pm 11.3$ & $290 \pm 17.4$ & $280 \pm 6.68$ & $285 \pm 19.6$ \\
Weight of liver $(\mathrm{g})$ & $8.1 \pm 1.68$ & $13.0 \pm 1.00^{*}$ & $8.8 \pm 0.75^{\star *}$ & $9.50 \pm 1.5^{\star *}$ & $10.3 \pm 1.12^{* *}$ \\
Relative weight of liver & 2.5 & $5.1^{*}$ & $3.03^{* *}$ & $3.39^{\star *}$ & $3.61^{* *}$ \\
\hline
\end{tabular}

${ }^{*}$ Significant as compared with control at $(P<0.05),{ }^{* *}$ significant as compared with DEN-induced liver damage at $(P<0.05)$.

Table 3. Effect of $C$. giladenesis on the (mean \pm SE) lipid profile for 10 weeks in albino rats $(n=8)$.

\begin{tabular}{|c|c|c|c|c|}
\hline \multirow{2}{*}{ Treatment } & \multicolumn{4}{|c|}{ Mean \pm SEM } \\
\hline & Cholest (mg/dl) & LDLc(mg/dl) & $\mathrm{TG}(\mathrm{mg} / \mathrm{dl})$ & $\mathrm{HDL}(\mathrm{mg} / \mathrm{dl})$ \\
\hline Control & $74.2 \pm 2.75$ & $18.2 \pm 0.80$ & $53.4 \pm 3.05$ & $62.0 \pm 3.57$ \\
\hline DEN & $114.6 \pm 14.1^{*}$ & $26.0 \pm 3.0$ & $64.6 \pm 12.1$ & $36.8 \pm 10.7^{*}$ \\
\hline Plant & $63.8 \pm 9.29^{\star *}$ & $19.2 \pm 1.25^{\star *}$ & $42.0 \pm 5.05$ & $64.4 \pm 7.32^{\star *}$ \\
\hline Preventive & $70.4 \pm 4.05^{\star \star}$ & $20.3 \pm 1.33^{\star \star}$ & $49.0 \pm 6.82$ & $63.8 \pm 4.38^{\star *}$ \\
\hline Treatment & $80.7 \pm 6.98^{\star \star}$ & $20.8 \pm 0.91^{* *}$ & $46.6 \pm 9.45$ & $60.8 \pm 4.96^{\star *}$ \\
\hline
\end{tabular}

*Significant as compared with control at $(P<0.05)$, ${ }^{* *}$ significant as compared with DEN- induced liver damage at $(P<0.05)$, Cholest.: cholesterol, LDL-c: low density lipoprotein lipids, TG: Triglyceride, HDL: High density lipoprotein lipids

\section{Statistical analysis}

Data were summarized as means \pm SEM. One way analysis of variance (ANOVA) followed by Dunnet's multiple comparison test was used to conduct the significance of association using statistical package for the social sciences (SPSS) program version 21 . Differences were considered significant at $P$ values of less than 0.05 .

\section{RESULTS}

\section{Hepatoprotective effect}

Methanolic extract of $C$. gileadenesis showed significant amelioration of DEN-induced liver injury as it reduced the level of liver function enzymes AST, ALT and ALP (Table
1). This effect was supported by reduction in the relative weight of liver and lipid profile (Tables 2 and 3 ) as well as tissue and hepatocytes improvements. In addition, $C$. gileadenesis showed significant reduction in platelets aggregation and lymphocyte levels as seen in Table 4 and 5. Moreover, continuous administration of $C$. gileadenesis in albino rats for 10 weeks counteracted the weight loss caused by DEN, and improved the health state of animals without harmful effect on blood glucose level as shown in Figures 1 and 2.

\section{Toxicological study}

There were no acute mortality and biochemical toxicity observed after oral administration of $C$. gileadenesis even 
Table 4. Effect of $C$. giladenesis on the (mean \pm SE) complete blood count (CBC) for 10 weeks in albino rats $(n=8)$.

\begin{tabular}{|c|c|c|c|c|c|c|}
\hline \multirow[b]{2}{*}{ Treatment } & \multicolumn{6}{|c|}{ Mean \pm SEM } \\
\hline & $\begin{array}{c}\mathrm{Hb} \\
(\mathrm{g} / \mathrm{dl})\end{array}$ & $\begin{array}{c}\text { RBC } \\
\left(\mathrm{X} 10^{\wedge 12} / \mathrm{L}\right) \\
\end{array}$ & $\begin{array}{c}\text { MCV } \\
\text { (Femtoliters) }\end{array}$ & $\begin{array}{c}\mathrm{MCH} \\
(\mathrm{pg})\end{array}$ & $\begin{array}{l}\mathrm{MCHC} \\
(\mathrm{g} / \mathrm{dl})\end{array}$ & $\begin{array}{l}\text { Platelets } \\
\left(X 10^{\wedge} 9 / L\right) \\
\end{array}$ \\
\hline$\overline{\text { Control }}$ & $16.0 \pm 0.45$ & $8.77 \pm 0.488$ & $52.0 \pm 0.23$ & $17.1 \pm 0.07$ & $31.6 \pm 0.65$ & $494.0 \pm 64.4$ \\
\hline DEN & $17.0 \pm 0.17$ & $9.87 \pm 0.298$ & $54.5 \pm 1.28$ & $17.3 \pm 0.29$ & $32.2 \pm 0.58$ & $837.0 \pm 126^{*}$ \\
\hline Plant & $16.1 \pm 0.39$ & $8.63 \pm 0.750$ & $53.7 \pm 2.07$ & $16.7 \pm 0.21$ & $31.9 \pm 0.56$ & $553.0 \pm 11.3^{* *}$ \\
\hline Preventive & $15.9 \pm 0.98$ & $8.35 \pm 9.428$ & $54.4 \pm 0.81$ & $17.8 \pm 0.57$ & $31.7 \pm 0.41$ & $593.064 .2^{* *}$ \\
\hline Treatment & $16.8 \pm 0.47$ & $9.19 \pm 0.257$ & $53.6 \pm 1.26$ & $17.2 \pm 0.14$ & $32.6 \pm 0.41$ & $616.0 \pm 30.6^{* *}$ \\
\hline
\end{tabular}

*Significant as compared with control at $(\mathrm{P}<0.05),{ }^{* *}$ significant as compared with DEN-induced liver damage at $(\mathrm{P}<0.05)$, Hb: hemoglobin, RBC: Red blood cell, MCV: mean cell volume, $\mathrm{MCH}$ : mean corpuscular hemoglobin. MCHC: mean corpuscular hemoglobin concentration.

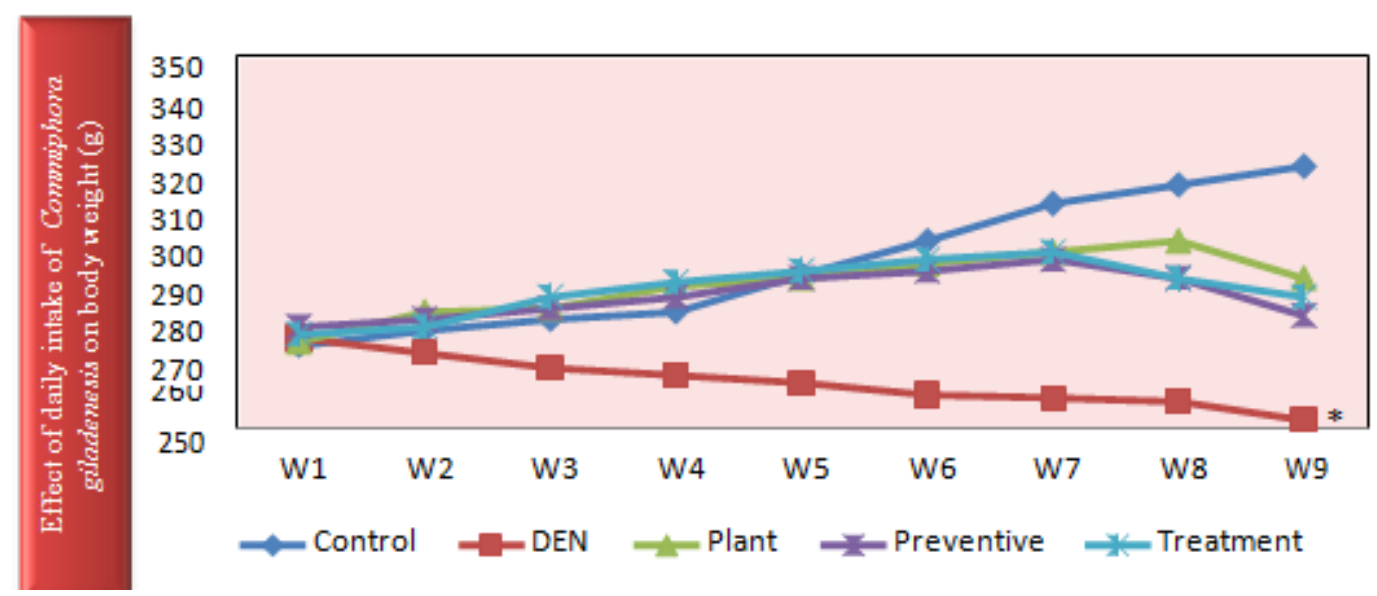

Figure 1. C. giladenesis on the (mean \pm SE) body weight $(g)$ for 10 weeks in albino rats $(\mathrm{n}=8),{ }^{*}$ Significant as compared with control at $(\mathrm{P}<0.05)$, W: week's number.
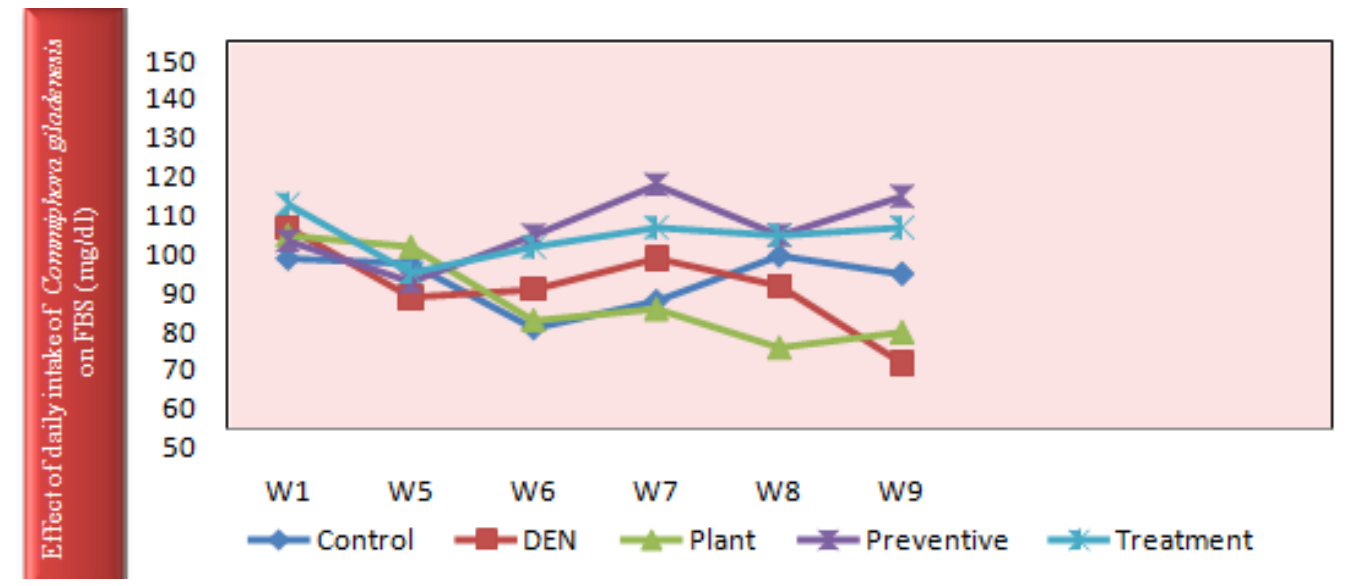

Figure 2. Effect of daily intake of $C$. giladenesis on the (mean $\pm \mathrm{SE}$ ) fasting blood sugar (mg/dl) for 10 weeks in albino rats.

at a dose of $3 \mathrm{~g} / \mathrm{kg}$. All animals were found to be normal at the end of $72 \mathrm{~h}$ with no significant differences between control and treated groups in the measured parameters (Tables 5 and 6). 
Table 5. Effect of $C$. giladenesis on DEN-induced alteration in CBC in male albino rats.

\begin{tabular}{lccccc}
\hline \multirow{2}{*}{ Treatment } & \multicolumn{5}{c}{ Mean \pm SE } \\
\cline { 2 - 6 } & T.WBC $(\times \mathbf{1 0} \mathbf{9} / \mathbf{L})$ & Lymphocyte (\%) & Monocyte (\%) & Neutrophil (\%) & Eosinophil (\%) \\
\hline Control & $9.1 \pm 0.63$ & $64.3 \pm 5.16$ & $0.7 \pm 0.16$ & $20.5 \pm 2.91$ & $1.7 \pm 0.29$ \\
DEN & $11.4 \pm 0.84^{*}$ & $80.6 \pm 5.08^{\star}$ & $0.9 \pm 0.23$ & $22.2 \pm 1.19$ & $1.9 \pm 0.23$ \\
Plant & $8.78 \pm 0.55^{\star *}$ & $60.8 \pm 2.39^{* *}$ & $0.7 \pm 0.16$ & $20.7 \pm 1.01$ & $1.5 \pm 0.33$ \\
Preventive & $9.52 \pm 0.92$ & $68.3 \pm 2.40^{* *}$ & $0.8 \pm 0.18$ & $19.5 \pm 1.42$ & $1.1 \pm 0.30$ \\
Treatment & $10.3 \pm 0.399$ & $67.6 \pm 2.91^{* *}$ & $0.6 \pm 0.20$ & $20.8 \pm 1.89$ & $1.3 \pm 0.14$ \\
\hline
\end{tabular}

${ }^{*}$ Significant as compared with control at $(P<0.05),{ }^{* *}$ significant as compared with DEN-induced liver damage at $(P<0.05)$, TWBC: total white blood cell.

Table 6. Acute toxicity study of extract of $C$. gileadenesis.

\begin{tabular}{lccc}
\hline Test & \multicolumn{3}{c}{ Mean \pm SE } \\
\hline Animal groups & Control & Extract $\mathbf{~ g} / \mathbf{k g}$ & Extract $\mathbf{~ g} / \mathbf{k g}$ \\
\hline Clinical observation & No effect & No effect & No effect \\
Body weight $(\mathrm{g})$ & $323.0 \pm 26.5$ & $314.0 \pm 15.0$ & $330.0 \pm 14.9$ \\
Pretreatment & $323.7 \pm 27.3$ & $314.8 \pm 15.1$ & $330.5 \pm 15.3$ \\
After 24 hours & $325.1 \pm 28.1$ & $316.2 \pm 14.9$ & $332.0 \pm 14.8$ \\
After 48hours & $325.9 \pm 28.3$ & $316.7 \pm 14.6$ & $334.5 \pm 15.3$ \\
After 72 hours & & & \\
Food intake (g) & $79.0 \pm 3.23$ & $76.1 \pm 3.48$ & $77.5 \pm 3.84$ \\
Pretreatment & $78.9 \pm 3.20$ & $77.8 \pm 2.19$ & $81.1 \pm 2.57$ \\
After 24 hours & $80.2 \pm 3.32$ & $78.6 \pm 2.70$ & $82.7 \pm 2.40$ \\
After 48hours & $81.0 \pm 3.46$ & $80.0 \pm 2.65$ & $89.6 \pm 3.17$ \\
After 72 hours & & & \\
Biochemical studies & $12.4 \pm 0.63$ & $11.9 \pm 1.07$ & $14.1 \pm 0.54$ \\
Hematology & $10.2 \pm 0.41$ & $10.5 \pm 0.29$ & $9.33 \pm 1.01$ \\
Hb (g/dl) & & & \\
Total W.B.C liver function enzymes & $62.3 \pm 19.4$ & $55.0 \pm 20.4$ & $37.3 \pm 11.3$ \\
AST & $56.0 \pm 19.5$ & $51.3 \pm 21.6$ & $39.7 \pm 8.66$ \\
ALT & & & \\
Fasting blood sugar & $119.3 \pm 4.66$ & $126.0 \pm 12.0$ & $113.7 \pm 9.56$ \\
Pretreatment & $117.5 \pm 13.9$ & $120.7 \pm 3.17$ & $91.0 \pm 6.51$ \\
Post -treatment & Normal & No change & No change \\
Histophathology study & Normal & No change & No change \\
Liver Heart & & &
\end{tabular}

\section{DISCUSSION}

In the present study, diethylnitrosamine was used as a model of hepatic injury. It is an $\mathrm{N}$-nitroso alkyl compound, categorized as a potent hepatotoxin and hepatocarcinogen in experimental animals (Figure 3a-j) (Jose et al., 1998). This compound is metabolized in liver by $\mathrm{P} 450$ enzymes to form reactive electrophiles which cause oxidative stress leading to cytotoxicity, mutagenicity and carcinogenicity (Archer, 1989). It is considered as a pollutant found in environment, foods, alcoholic beverages and pharmaceutical agents (Sivaramkrishnan et al., 2008; Gupta et al., 2010).

The result of this study showed that DEN elevated significantly the liver function enzymes as well as it caused severe histopathological changes in the liver tissues. DEN led marked elevation of serum enzyme levels of AST, ALT and ALP is good indication of hepatocellular damage. However, elevation of these enzymes may lead to liver necrosis due to leakage of these enzymes to blood stream (Ala-Kokko et al., 1987; Al-Rejaie et al., 2009). Furthermore, an accumulation of connective tissue 

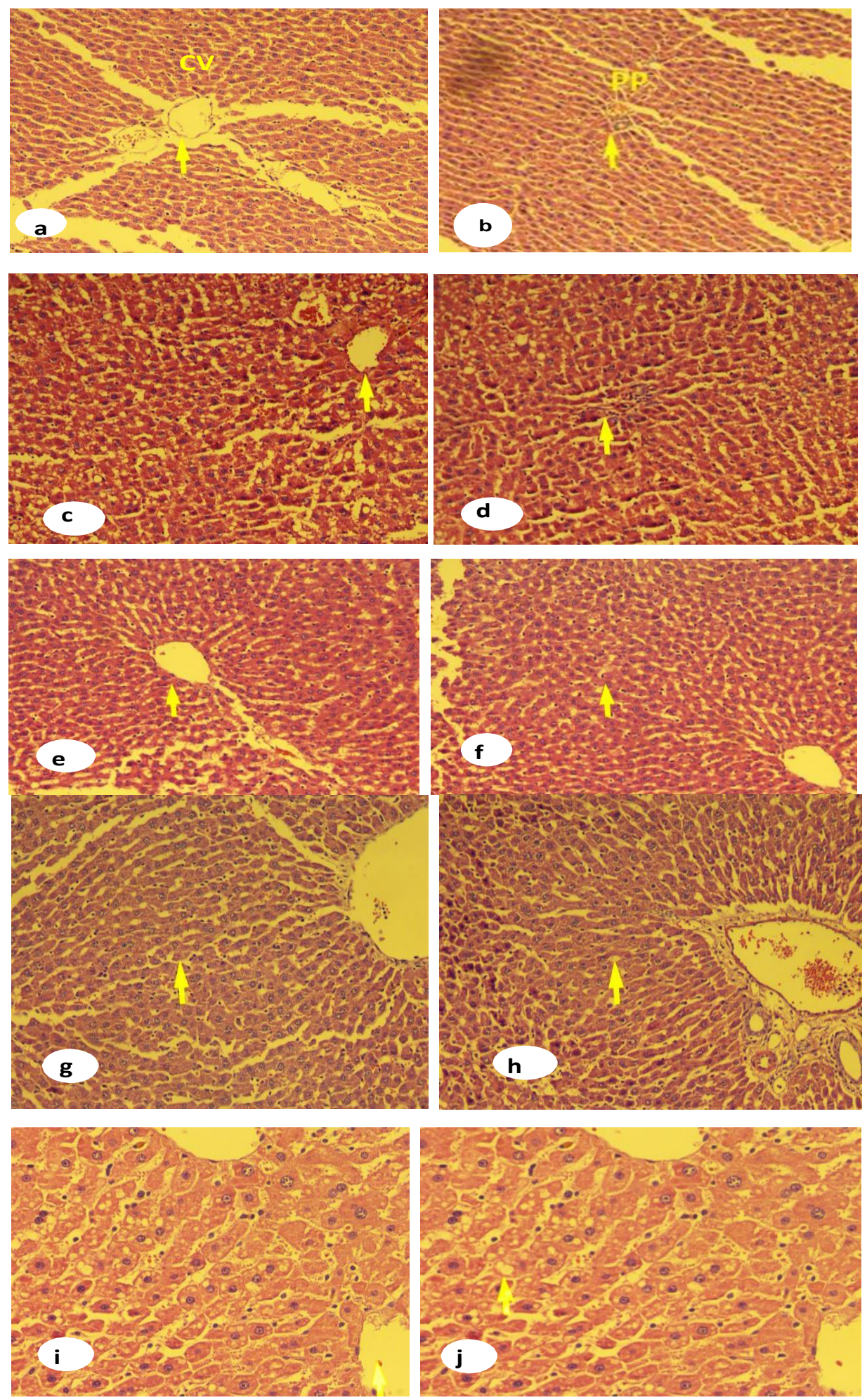

Figure 3. a and b: Control group section showing liver with preserved architecture with normal preportal, central vein and trabeculae of hepatocytes separated by blood sinusoids (H\&E; original magnification: $X 200$ ); $c$ and d: DEN treated group, showing inflammatory cells, the hepatocytes show macro and micro steatosis involving zone 3 in few acinus (H\&E; original magnification: X 200); e and f: Plant treated group, showing normal liver architecture of central vein and mid zone (H\&E; original magnification: X 200); $g$ and h: Preventive group, showing marked improvement of liver with no evidence of steatosis in mid zone and preportal area (H\&E; original magnification: $X 200)$; i and $\mathrm{j}$ : Treatment group showing marked improvement with mild steatosis in zone3 (H\&E; original magnification: X 200). 
protein especially collagen, have been reported in DEN induced liver injury (George and Chandrakasan, 1996). Moreover, decreased synthesis of collagenolytic in the impaired hepatocytes may cause an accumulation of collagen (George et al., 2001). All these effects were ameliorated by the using of methanolic extract of $C$. gileadenesis bark. This plant showed significant preventive and therapeutic effects against DEN-induced hepatic injury through reduction of the liver function enzymes like AST, ALT and ALP as well as lipid profile especially cholesterol, LDL-C supported by the histopathological tissue improving in commiphora-treated groups.

However, the mechanism underlying the improvement of hepatic functions after continuous using of this plant may be referred to prevent the formation of reactive metabolite of DEN through direct inhibition of the hepatic cytochrome P450, additionally, it inhibits lipid peroxidation processes, stabilizes the hepatocyte membrane and enhances protein synthesis (Al-Howiriny et al., 2003). The presence of phytochemical antioxidant constituents like flavonoids, volatile oils, saponins, triterpenes and sterols are considered as key role for the protective effects and free radical scavengers in this plant (Vogel, 1977; Kikuzaki et al., 2000).

Regarding the effect of $C$. gileadenesis on complete blood count, it was found that this plant has significant reduction of platelets levels caused by DEN-induced toxicity. The precise reason for diminished platelets aggregation is still unknown. This worthwhile and remarkable anti-platelets activity may be due to either anti-inflammatory effect (Al-Howiriny et al., 2003) through the action on inflammatory mediators like thromboxane A2, 5HT and ADP or direct action on GPIlb/lla receptors of platelets.

Conversely, the outcome of the present study was that, this plant counteracted the weight loss in DEN- treated group when it was administered for preventive or therapeutic purposes, this effect was not accompanied with any change in fasting blood sugar level. It suggested that this plant is characterized by appetite modulating effect without harmful metabolic changes as it reduced lipid profile especially cholesterol and low density lipoprotein (bad lipids). In contrary, it raised high density lipoprotein level which is known as a good lipid (AlAmoudi, 2009). All these magic effects make this plant as a novel complementary medicine for many ailments. Additionally, beside its worthwhile health benefits, it is also considered as a safe plant assessed by preliminary toxicological study. It saves up to $3 \mathrm{~g} / \mathrm{kg} / \mathrm{d}$ ( 2.5 fold of the dose used) without any observational, biochemical side effects and/or histopathological changes.

\section{Conclusion}

From the outcomes of the present study, it is suggested that $C$. gileadenesis possesses protective effect against
DEN-induced liver injury and anti -platelets activity. The presence of phytochemical antioxidant constituents in this plant like flavonoids, volatile oils, saponins, triterpenes and sterols may be responsible for its protective effects as they working as free radical scavengers. Additionally, the toxicological study showed that this plant can be used safely without any harmful effects. Further studies using more technical methods to elucidate the exact constituent (s) responsible for these benefits without side effects are required in order to approve and expand these findings.

\section{Conflict of interests}

The authors have not declared any conflict of interests.

\section{ACKNOWLEDGEMENT}

The authors would like to thank the College of Pharmacy who partially funded this study. Special thanks to Professor Lenny Rhine for his invaluable assistance to revise and edit this paper, Dr. Faruk Alqadasi for statistics analysis, Aulaqi specialized Med. Lab and everyone who worked hard for the successful completion of this work.

\section{REFERENCES}

Abicht K, El-Samalouti V, Junge W, Kroll M, Luthe H, Treskes M, Klein $G$ (2001). Multicenter evaluation of new GGT and ALP reagents with new reference standardization and determination of $37^{\circ} \mathrm{C}$ reference intervals. Clin. Chem. Lab. Med. 39(Suppl):S346

Al Howiriny T, Mohammed A, Al-Yahya, Mansour S, Al-Said, Kama I, ElTahir EH, S Rafatullah (2004). Studies on the pharmacological activities of an ethanol extract of Balessan (Commiphora opoblsamum). Pak. J. Biol. Sci. 7(11):1933-1936.

Ala-Kokko L, Pihlajaniemi T, Myers JC, Kivirikko KI, Savolainen ER (1987). Gene expression of type I, III and IV collagens in hepatic fibrosis induced by dimethylnitrosamine in the rat. Biochem. J. 244:7579.

Al-Amoudi NS (2009). Hypocholesterolemic effect of some plants and their blend as studied on albino rats. Int. J. Food Saf. Nutr. Public Health 2(2):176.

Al-Howiriny TA, Al-Sohaibani MO, El-Tahir KH, Rafatullah S (2003). Preliminary evaluation of the anti-inflammatory and anti-hepatotoxic activities of 'Parsley' Petroselinum crispum in rats. J. Nat. Remed. 3(1):54-62.

Al-Rejaie S (2009). Progression of diethylnitrosamine-induced hepatic carcinogenesis in carnitine- depleted rats. World J. Gastroenterol. 15(11):1373-1380.

Altkofer W, Braune S, Ellendt K, Kettl-Grömminger M, Steiner G (2005). "Migration of nitrosamines from rubber products--are balloons and condoms harmful to the human health?" Mol. Nutr. Food Res. 49(3):235-8.

Archer MC (1989). Mechanisms of action of $\mathrm{N}$-nitrosocompounds. Cancer Surv. 8:241-250.

Bachoric P (2000). Measurement of Low-Density-Lipoprotein. In: Handbook of Lipoprotein Testing (eds. Rifai, Warnick and Dominiczak), 2nd edition, AACC press. pp. 245-263.

George J, Chandrakasan G (1996). Molecular characteristics of dimethylnitrosamine induced fibrotic liver collagen. Biochem. Biophys. Acta 1292:215-222.

George J. Rao K, Stern R, Chandrakasan (2001). Diethylnitrosamineinduced liver injury in rats: the early deposition of collagen. Toxicology $156: 129-138$ 
Gupta C, Vikram A, Tripathi DN, Ramarao P, Jena GB (2010). Antioxidant and antimutagenic effect of quercetin against DEN induced hepatotoxicity in rat. Phytother. Res. 24(1):119-128.

Jaykaran PB, Kantharia N, Yadav P, Panwar A (2008). Acute toxicity study of an aqueous extract of Ficus racemosa Linn. bark in albino mice. Internet J. Toxicol. 6(1).

Jones SHL (1924). ed., The Geography of Strabo, Cambridge, MA: Harvard University press; London; William Heinemann, Ltd.

Jose JK, Kuttan R, Bhattacharaya RK (1998). Effect of Emblica officinalis extract on hepatocarcinogenesis and carcinogen metabolism. J. Clin. Biochem. Nutr. 25:31-39.

Kalaiselvan A, Gokulakrishnan K, Anand T, Akhilesh U, Velavan S (2013). Preventive Effect of Shorea Robusta Bark Extract against Diethylnitrosamine-Induced Hepatocellular Carcinoma in Rats. Int. Res. J. Med. Sci. 1(1):2-9.

Kikuzaki H, Sato A, Mayahara Y, Natakani N (2000). Galloylhlucosides from berries of Pimento dioica. J. Natural Prod. 63(6):749.

Knudson PE, Weinstock RS (2001). Carbohydrates. In: Henry JB, ed. Clinical Diagnosis and Management by Laboratory Methods. 20th ed. Philadelphia: WB Saunders. pp. 211-223

Magee PN, Barnes JM (1967). Carcinogenic nitroso compounds. Adv. Cancer Res. 10:163-246.

Mohammed F, Ahmed S, Sultan, Al-shimaa MA (2014). Chemopreventive and therapeutic effect of capsaicin against diethylnitrosamine induced liver injury and hepatocellular carcinoma in rats. Int. J. Biol. Pharm. Res. 5(8):630-642.

Pisani T, Gebski CP, Leary ET, Warnick GR, Ollington JF (1995). Accurate direct determination of low-density lipoprotein cholesterol using an immunoseparation reagent and enzymatic cholesterol assay. Arch. Pathol. Lab. Med. 119:1127-35)

Pliny G (1989). Naturalis Historia (Jones WHS, translator). LCL, London. Schumann G, Bonora R, Ceriotti F, Férard G, Ferrero CA, Franck PF (2002). IFCC Primary Reference Procedures for the Measurement of Catalytic Activity Concentrations of Enzymes at $37^{\circ} \mathrm{C}-$ Part 4. Reference Procedure for the Measurement of Catalytic Activity Concentrations of Alanine Aminotransferase. Clin. Chem. Lab. Med. 40(7):718-724.
Sivaramkrishnan V, Shilpa PNM, Kumar VRP Devaraj SN (2008). Attenuation of $\mathrm{N}$-nitrosodiethylamine- induced hepatocellular carcinogenesis by a novel flavonol-Morin. Chem. Biol. Interact 171:7988.

Sonntag O, Scholer A (2001). Drug interferences in clinical chemistry: recommendation of drugs and their concentrations to be used in drug interference studies. Ann Clin. Biochem. 38:376-385.

Stein EA, Myers GL (1995). National Cholesterol Education Program recommendations for triglyceride measurement: executive summary. The National Cholesterol Education Program Working Group on Lipoprotein Measurement. Clin. Chem. 41:1421-1426.

Swann PF, Magee PN (1971). Nitrosamine induced Carcinogenesis. Biochem. J. 125:841-847.

Vogel G (1977). Natural substances with effects on the liver. In: Wagner B, Wolff R (Eds). "New Natural Products and Plant Drugs with Pharmacological, Biological or Therapeutic Activity." Springer-Verlag, Heidelberg. pp. 249-256.

Zohary M (1973). Geobotanical Foundations of the Middle East, volumes 1, 2. Gustav Fischer Verlag, Stuttgart, Germany. ASIN B0006CB7Z4.

Zohary M (1982). Plants of the Bible: A Complete Handbook to All the Plants with 200 Full-Color Plates Taken in the Natural Habitat. London, UK: Cambridge University Press. 